\title{
Analisa Pengaruh Variasi Merek Kampas Rem Tromol Dan Kecepatan Sepeda Motor Honda Supra X125 Terhadap Keausan Kampas Rem
}

\author{
Ahmad Multazam ${ }^{\star}$, Achmad Zainuri $^{\star *}$, Sujita $^{\star * *}$ \\ Jurusan Teknik Mesin, Fakultas Teknik, Universitas Mataram \\ Jalan Majapahit No.62 Mataram
}

\begin{abstract}
Brake is one component of a motor vehicle that serves to slow or stop the study aims to determine the value of the wear of each brand of brake drum caused by variations in the speed of the motorcycle Honda Supra X125 on the braking load $6 \mathrm{~kg}$.

Brake that is used in this study there are three variations of the brand is a brand HONDA GENUINE PART, ASPIRA, and KOMACHI with variations at 40,50 and $60 \mathrm{~km} / \mathrm{h}$ and braking load $6 \mathrm{~kg}$. The research was conducted in two phases, namely the field of testing and measuring brake wear in the lab. Metrology using a profile projector, in addition to the Rockwell hardness testing is also performed to determine the hardness of each brand of brake lining before and after testing higher speeds with the same braking load time, braking distance and the wear rate also increased.

From the research results smallest brake lining wear occurs there at a speed of $40 \mathrm{~km} /$ $h$ and braking load $6 \mathrm{~kg}$. Genuine Parts for the Honda brand it wear amounted to $1.574 \times 10-5$ $\mathrm{mm} / \mathrm{sec}$, while the brand Aspira it wear $8.47 \times 10-5 \mathrm{~mm} / \mathrm{sec}$ and brands Komachi it wear $3.500 \times 10-5 \mathrm{~mm} / \mathrm{sec}$. Largest brake wear occurs at a speed of $60 \mathrm{~km} / \mathrm{h}$ and braking load 6 $\mathrm{kg}$. Genuine Parts for the Honda brand is equal to $2.373 \times 10-5 \mathrm{~mm} / \mathrm{sec}$, while the brand Aspira it wear $3.626 \times 10-5 \mathrm{~mm} / \mathrm{sec}$ and brands Komachi it wear $3.701 \times 10-5 \mathrm{~mm} / \mathrm{sec}$.
\end{abstract}

Keywords: Brand brake lining, brake lining wear, speed, time and braking distance.

\section{Pendahuluan}

\section{Latar Belakang}

Indonesia merupakan Negara berkembang dan memiliki kekayaan alam yang melimpah, serta kebutuhan akan teknologi baru semakin meningkat untuk memperlancar system perekonomian. Salah satu teknologi yang berkembang pesat adalah bidang otomotif trutama sepeda motor, dengan semakin beragamnya tipe, merk, dan jumlah kendaraan bermotor, kebutuhan akan spare parts otomotif juga semakin meningkat salah satu komponen sepeda motor yang perlu diperhatikan adalah kampas rem.

Kanpas rem merupakan salah satu komponen kendaraan bermotor yang berfungsi untuk memperlambat atau menghentikan laju kendaraan khususnya kendaraan darat.

Untuk mendapatkan pengereman yang maksimal maka dibutuhkan kampas rem dengan kemampuan pengereman yang baik, Kualitas kampas rem dipengaruhi oleh kekerasan dan bahan kampas rem (Amelia dan Suhartojo, 2002). Disamping itu semakin tinggi laju kendaraan maka semakin besar pula beban pengereman yang berdampak pada keausan permukaan kampas rem.

Terdapat beberapa merek kanpas rem yang beredar dipasaran, suatu kode atau tanda pada komponen kampas rem ada yang bertuliskan OEM (Original Equipment Manufactured) yaitu kampas rem yang terpasang pada saat kita membeli kendaraan baru dari dealer, Ada lagi tanda OES (Original Equipment Spare part) yaitu kampas rem yang digunakan sebagai pengganti kampas rem OEM, kampas rem ini dibuat oleh pabrikan OEM yang memiliki persamaan pada formula, proses pembuatan, kualitas dan bahan yang sama dengan kampas rem OEM.

Namun ada suku cadang yang disebut After market yaitu kampas rem yang beredar di pasaran dengan kualitas yang beragam, misalnya lebih rendah dari OEM atau lebih tinggi dari OEM. Satu lagi yang sering kita jumpai yaitu sebutan Genuine, tanda tersebut pada dasarnya adalah kampas rem tergolong ke dalam kategori after market, istilah genuine hanya untuk membedakan antara asli dan palsu (Arief Tri Waskito2, 2008).

Mengingat masyarakat indonesia berdasarkan kemampuan ekonominya sangat beragam dan umumnya bila mencari komponen akan mencari yang murah tanpa memperhatikan kualitas yang berkaitan dengan keselamatan jiwa ( Wawan Kartiwa Haroen). 
Oleh karena itu, dalam tugas akhir ini membahas topic tentang "Analisa Pengaruh Variasi Merek Kampas Rem Tromol Dan Kecepatan Sepeda Motor Honda Supra X125 Terhadap Keausan Kampas Rem" dengan tujuan agar dapat digunakan sebagai acuan oleh masyarakan untuk memilih merek kampas rem yang baik.

\section{Tujuan Penelitian}

Adapun tujuan penelitian ini adalah: Untuk mengetahui nilai keausan dari masing masing merek kampas rem tromol yang diakibatkan oleh variasi kecepatan sepeda motor Honda Supra X125 pada beban pengereman $6 \mathrm{~kg}$.

\section{Teori}

\section{Konsep Dasar Pengereman}

Sistem rem dalam suatu kendaraan sepeda motor termasuk sistem yang sangat penting karena berkaitan dengan faktor keselamatan berkendara. Prinsip kerja sistem rem adalah mengubah tenaga kinetik menjadi panas dengan cara menggesekkan dua buah benda yang berbeda berputar sehingga putarannya akan melambat. Oleh sebab itu komponen rem yang bergesekan ini harus tahan terhadap gesekan (tidak mudah aus), tahan panas dan tidak mudah berubah bentuk pada saat bekerja dalam suhu tinggi (Sumber : Hardianto, 2008).

Semakin tinggi kemampuan kendaraan tersebut melaju maka semakin tinggi pula tuntutan kemampuan sistem rem yang lebih handal dan optimal untuk menghentikan atau memperlambat laju kendaraan. Untuk mencapainya diperlukan perbaikan-perbaikan dalam system pengereman tersebut. Sistem rem yang baik adalah sistem rem yang jika dilakukan pengereman baik dalam kondisi apapun pengemudi tetap dapat mengendalikan arah dari laju kendaraannya (Sumber : Hardianto, 2008).

\section{Fungsi Rem}

Sistem rem dalam teknik Otomotif adalah suatu sistem yang berfungsi untuk:

1. Mengurangi kecepatan sampai menghentikan kendaraan.

2. Mengontrol kecepatan selama berkendara.

3. Untuk menahan kendaraan pada saat parkir dan berhenti pada jalan yang menurun atau menanjak.

\section{Rem Tromol ( Brake Drum )}

Tipe drum, rem ini terdiri dari sepasang kampas rem yang terletak pada piringan yang tetap (tidak ikut berputar bersama roda), dan drum yang berputar bersama roda. Dalam operasinya setiap kampas rem akan bergerak radial menekan drum sehingga terjadi gesekan antara drum dan kampas rem lihat gambar 2.2 dibawah ini (Hardianto, 2008).

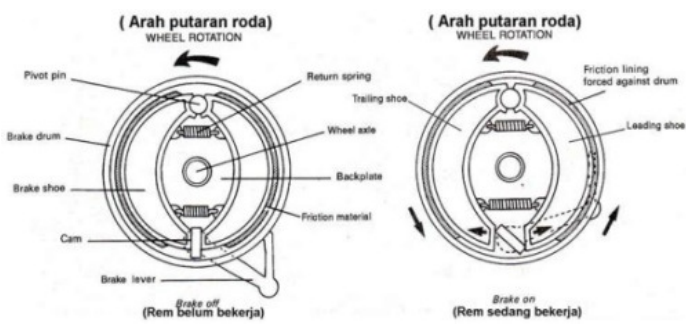

Gambar 1. Rem tromol. ( Jalius Jama dkk, 2008 )

Pada rem tromol, penghentian atau pengurangan putaran roda dilakukan dengan adanya gesekan antara sepatu rem dengan tromolnya. Pada saat tuas rem tidak ditekan sepatu rem dengan tromol tidak saling kontak. Tromol rem berputar bebas mengikuti putaran roda, tetapi pada saat tuas rem ditekan lengan rem memutar cam pada sepatu rem sehingga sepatu rem menjadi mengembang dan bergesekan dengan tromolnya. Akibatnya putaran tromol dapat ditahan atau dihentikan (Hardianto, 2008).

\section{Komponen Utama System Rem Tromol}

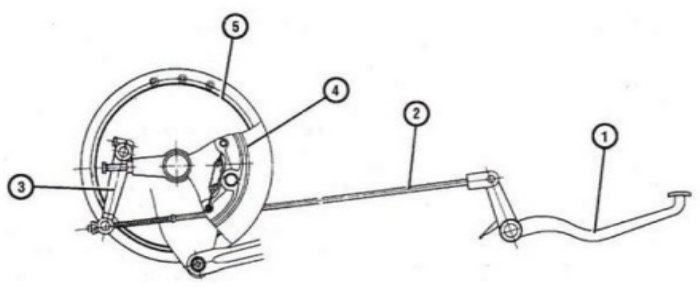

Gambar 2. Rem Tromol dan Kelengkapannya Brake Pedal (Pedal Rem), (2) Operating Rod (Batang Penghubung), (3) Brake Lever (Tuas Rem), (4) Brake Shoe (sepatu rem), dan (5) Drum (Tromol). ( Jalius Jama dkk, 2008 )

\section{Karaktristik Bahan Kampas Rem Material Kampas Rem}

Bahan baku yang digunakan pada kampas rem standar umumnya terdiri dari serbuk aluminum, grafit, barium, alumina, 
asbestos, cashew dust, NBR powder, dan lainnya sebagai bahan penguat atau serat sedangkan bahan untuk matriknya atau pengikat adalah resin phenolic. Serat dalam komposit berperan sebagai bagian utama yang menahan beban serta memberikan sifat kekakuan, kekuatan, stabilitas panas dalam komposit.

Matrik dalam komposit berperan sebagai pengikat serat dan mendistribusikan tegangan pada saat pembebanan. Bahan matrik yang sering digunakan dalam pembuatan komposit adalah matrik polimer, adapun jenisnya antara lain thermoset dan thermoplastic. Yang termasuk thermoset antara lain epoxy, polyester, dan phenolic. Yang termasuk thermoplastic antara lain polyetylene, dan polypropylene (Tri Maulana, 2010).

\section{Proses Produksi Kampas Rem}

Berdasarkan proses pembuatannya, kampas rem (brakeshoes) sepeda motor bahan penguatnya (reinforced) terdiri atas partikel yang tersebar merata dalam matriks yang berfungsi sebagai pengikat, sehingga menghasilkan bentuk solid yang baik. Melalui proses penekanan sekaligus pemanasan pada saat pencetakan (sintering) akan dihasilkan kekuatan, kekerasan serta gaya gesek yang semakin meningkat. Pemanasan dilakukan pada temperatur berkisar antara $130^{\circ} \mathrm{C}-150^{\circ} \mathrm{C}$, yang menyebabkan bahan tersebut akan mengalami perubahan struktur dimana antara partikel satu dengan yang lain saling melekat serta akan diperoleh bentuk solid yang baik dan matriks pengikat yang kuat (Wawan Kartiwa).

\section{Sifat Mekanik Kampas Rem}

Masing-masing tipe sepeda motor memiliki bentuk serta kualitas bahan kampas rem khusus. Secara umum bagian-bagian kampas rem terdiri dari daging kampas (bahan friksi), dudukan kampas (body brake shoe) dan 2 buah spiral. Pada aplikasi sistem pengereman otomotif yang aman dan efektif, bahan friksi harus memenuhi persyaratan minimum mengenai unjuk kerja, noise dan daya tahan.

Bahan rem harus memenuhi persyaratan keamanan, ketahanan dan dapat mengerem dengan halus. Selain itu juga harus mempunyai koefisien gesek yang tinggi, keausan kecil, kuat, tidak melukai permukaan roda dan dapat menyerap getaran. Sifat mekanik menyatakan kemampuan suatu bahan (seperti komponen yang terbuat dari bahan tersebut) untuk menerima beban/gaya/energi tanpa menimbulkan kerusakan pada bahan/komponen tersebut.

Untuk mendapatkan standar acuan tentang spesifikasi teknik kampas rem, maka nilai kekerasan, keausan, bending dan sifat mekanik lainnya harus mendekati nilai standar keamanannya.

\section{Pengujian Spesimen \\ Pengujian Keausan Lelah} Keausan lelah

merupakan mekanisme yang relatif berbeda dibandingkan dua mekanisme sebelumnya, yaitu dalam hal interaksi permukaan. Baik keausan adhesive maupun abrasif melibatkan hanya satu interaksi sementara pada keausan lelah dibutuhkan interaksi multi. Gambar 2.9 memberikan skematis mekanisme keausan lelah. Permukaan yang mengalami beban berulang akan mengarah pada pembentukan retak-retak mikro (t1). Retak-retak tersebut pada akhirnya menyatu (t2) dan menghasilkan pengelupasan material ((t3). Tingkat keausan sangat tergantung pada tingkat pembebanan ( Imam Setiyanto, 2009).
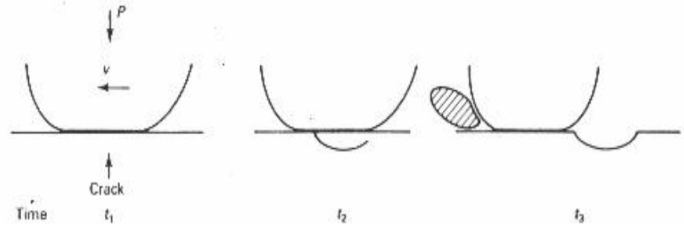

Gambar 3. Ilustrasi skematis keausan lelah (Yuwono, 2008)

\section{Pengujian Kekerasan}

Pada pengujian kekerasan menurut Rockwell kekerasan bahan ditentukan dari perlawanan terhadap pengubah bentuk tetap dengan pembekasan. Bekas ini disebabkan oleh suatu benda yang lebih keras dari pada bahan yang akan diuji dan dikala pembekasan itu sendiri hampir tidak mengalami perubahan bentuk (sumber : Imam Setiyanto, 2009).

\section{Pengujian Kekerasan Rockwell}

Berbeda dengan metode Brinell dan Vickers dimana kekerasan suatu bahan dinilai dari diameter/diagonal jejak yang dihasilkan maka metode Rockwell merupakan uji kekerasan dengan pembacaan langsung (direct-reading). Metode ini banyak dipakai dalam industry karena pertimbangan praktis. Variasi dalam beban dan indetor yang 
digunakan membuat metode ini memiliki banyak macamnya.

Metode yang paling umum dipakai adalah Rockwell B (dengan indentor bola baja berdiameter $1 / 6$ inci dan beban $100 \mathrm{~kg}$ ) dan Rockwell C (dengan indentor intan dengan beban $150 \mathrm{~kg}$ ). Walaupun demikian metode Rockwell lainnya juga biasa dipakai. Oleh karenanya skala kekerasan Rockwell suatu material harus dispesifikasikan dengan jelas. Contohnya $82 \mathrm{HRF}$, yang menyatakan material diukur dengan skala $F$ : indentor $1 / 6$ inci dan beban $60 \mathrm{~kg}$. Berikut ini diberikan Tabel 2.1 yang memperlihatkan perbedaan skala dan range uji dalam skala Rockwell (Akhmad Herman Y., 2009).

Tabel 1. Skala pada Metode Uji Kekerasan Rockwell

\begin{tabular}{|c|c|c|c|}
\hline SCALE & $\begin{array}{l}\text { MANOR LOAD. } \\
\text { KG }\end{array}$ & $\begin{array}{l}\text { TYPE OF } \\
\text { INDENTER }\end{array}$ & TYPICAL MATERIALS TESTED \\
\hline A & 60 & Diamond cone & $\begin{array}{l}\text { Extremely hard materials, tungsten } \\
\text { carbides, etc. }\end{array}$ \\
\hline B & 100 & $1 / 10^{*}$ ball & $\begin{array}{l}\text { Medium hard materials, low- and } \\
\text { medium-carbon steels, brass, } \\
\text { bronze, etc. }\end{array}$ \\
\hline c & 150 & Diamond cone & $\begin{array}{l}\text { Hardened steels, hardened and } \\
\text { tempered alloys }\end{array}$ \\
\hline o & 100 & Diamond cone & Case-hardened steel \\
\hline E & 100 & $1 / s^{*}$ ball & $\begin{array}{l}\text { Cast iron, aluminum and magnesium } \\
\text { alloys }\end{array}$ \\
\hline$F$ & 60 & $1 / 10^{\prime \prime}$ ball & Annealed brass and copper \\
\hline G & 150 & $1 / 10^{\prime \prime}$ ball & $\begin{array}{l}\text { Beryllium copper, phosphor } \\
\text { bronze, etc. }\end{array}$ \\
\hline H & 60 & $\% "$ ball & Aluminum sheet \\
\hline$k$ & 150 & $1 / a^{*}$ ball & Cast iron, aluminum alloys \\
\hline L & 60 & $1 / 4$ ball & Plastics and soft metals such as lead \\
\hline M & 100 & $y / x^{*}$ ball & Same as $L$ scale \\
\hline p & 150 & $1 / 4$ ball & Same as L scale \\
\hline R & 60 & $y / z^{2}$ ball & Same as L scale \\
\hline s & 100 & $1 / z^{*}$ ball & Same as L scale \\
\hline $\mathrm{v}$ & 150 & $1 / z^{*}$ ball & Same as L scale \\
\hline
\end{tabular}

\section{Metode Penelitian}

Prosedur penelitian yang akan dilakukan oleh penulis dalam rangka mengumpulkan data hingga penyelesaian masalah dalam penelitian ini adalah sebagai berikut :

1. Memasang kampas rem / benda uji yang akan diuji.

2. Menyetel penyetel rantai agar tetap posisi sama disetiap melakukan pengujian.

3. Mengukur jarak main tuas pengereman agar tetap sama disetiap kali melakukan pengujian dengan jarak $3 \mathrm{~cm}$.

4. Ikat beban pengereman tepat diposisi bawah pedal rem kemudian tahan dengan tangan yang di sambung dengan tali seperti gambar dibawah ini :
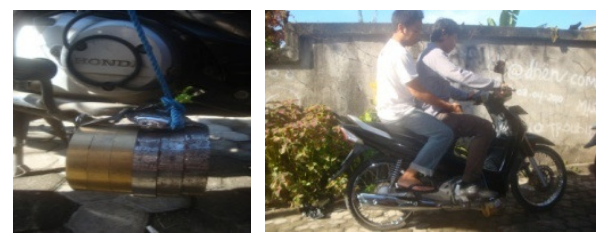

\section{Gambar 4. Posisi beban pengereman di sepeda motor.}

5. Hidupkan dan jalankan speda mtor Setelah kecepatan konstan misal pada kecepatan $60 \mathrm{~km} / \mathrm{jam}$, memberi aba - aba agar beban pengereman dan handle gas motor dilepas serta stopwatch di hidupkan secara bersamaan dimana pelepasan beban dan pengoperasian stopwatch dilakukan oleh penumpang di belakang.

6. Menghidupkan stopwatch mulai dari pelepasan beban pengereman sampai motor berhenti.

7. Mengukur secara manual jarak pengereman aktual yang di dapat.

8. Mencatat hasil penelitian saat motor sudah berhenti, dimana variabel yang dicatat yaitu variabel waktu dan jarak aktual.

9. Mengulang tahap 1 sampai 6 dengan 3 variasi merek kampas rem dan 3 variasi kecepatan dengan menggunakan 9 kampas rem.

10. Melakukan pengukuran ketebalan kampas rem setelah diuji untuk setiap 20 kali pengujian dengan menggunakan Profile Proyektor stelah itu menggambarkan kembali dimensi setelah pengujian 20 kali pengereman di autocad. hasil pengukuran sebelumnya dijadikan sebagai titik acuan untuk pengukuran selanjutnya.

11. Mencatat hasil masing masing keausan setiap kampas rem.

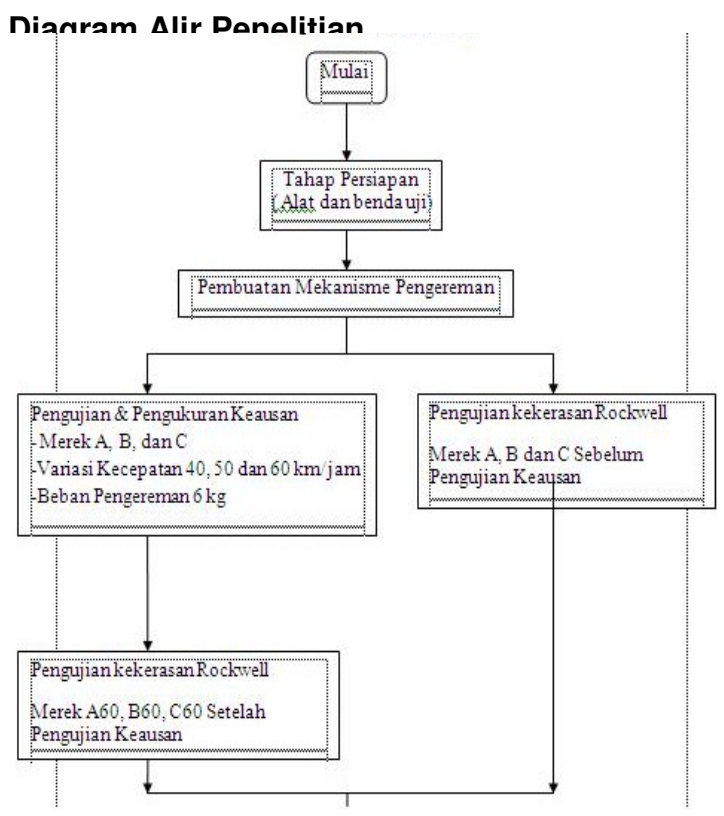


Hasil Dan Pem

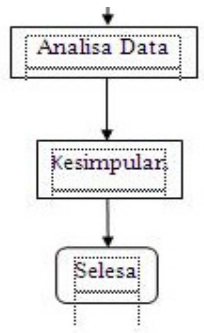

Hasil pengujian pada penelitian ini diperoleh berdasarkan prosedur yang telah ditetapkan dalam metode penelitian. Hasil yang akan disajikan menyangkut tentang besarnya keausan kampas rem tromol yang dihasilkan dari variasi marek kampas rem dan kecepatan sepeda motor Honda Supra X 125 pada beban pengereman $6 \mathrm{~kg}$.

\section{Hasil Pengujian Kekerasan Kampas Rem Sebelum Pengujian Keausan}

Pada pengujian kekerasan ini dilakukan dengan pengujian kekerasan rockwell dengan indentor bola baja ukuran diameter 1/16 inchi pengujian dilakukan 5 kali pengambilan data pada setiap merek kemudian dirata-ratakan, hasil rata-rata tersebut dapat dilihat pada tabel 2.

Tabel 2. Hasil pengujian kekerasan Rockwell sebelum pengujian keausan.

\begin{tabular}{|c|c|c|c|c|c|}
\hline No & $\begin{array}{c}\text { Merek } \\
\text { kampas rem }\end{array}$ & $\begin{array}{c}\text { Beban } \\
(\mathrm{kg})\end{array}$ & $\begin{array}{c}\text { D } \\
\text { (inchi) }\end{array}$ & \multicolumn{2}{|c|}{$\begin{array}{c}\begin{array}{c}\text { Kekerasan } \\
\text { (HRF) }\end{array} \\
\end{array}$} \\
\hline \multirow{5}{*}{1} & & 6 & $1 / 16$ & 1 & 88 \\
\hline & & 6 & $1 / 16$ & 2 & 101 \\
\hline & HONDA & 6 & $1 / 16$ & 3 & 103 \\
\hline & GENUIN & 6 & $1 / 16$ & 4 & 102 \\
\hline & PARTS & 6 & $1 / 16$ & 5 & 85 \\
\hline \multicolumn{4}{|c|}{ Kekerasan rata-rata } & & 95,8 \\
\hline \multirow{6}{*}{2} & \multirow{5}{*}{ ASPIRA } & 6 & $1 / 16$ & 1 & 58 \\
\hline & & 6 & $1 / 16$ & 2 & 69 \\
\hline & & 6 & $1 / 16$ & 3 & 71 \\
\hline & & 6 & $1 / 16$ & 4 & 67 \\
\hline & & 6 & $1 / 16$ & 5 & 55 \\
\hline & \multicolumn{3}{|c|}{ Kekerasan rata-rata } & & 64 \\
\hline \multirow{6}{*}{3} & \multirow{5}{*}{ KOMACHI } & 6 & $1 / 16$ & 1 & 48 \\
\hline & & 6 & $1 / 16$ & 2 & 56 \\
\hline & & 6 & $1 / 16$ & 3 & 61 \\
\hline & & 6 & $1 / 16$ & 4 & 49 \\
\hline & & 6 & $1 / 16$ & 5 & 47 \\
\hline & \multicolumn{3}{|c|}{ Kekerasan rata-rata } & & 52,2 \\
\hline
\end{tabular}

Hasil Pengujian kekerasan dari tiga variasi merek kampas rem sebelum pengujian keausan dilakukan di 5 titik. Kekerasan dari titik 1 sampai 5 berbeda-beda. Permukaan kampas rem pada posisi tengah lebih tinggi kekerasannya dibandingkan dipinggir dikarenakan pengaruh produksi. Pada saat proses hot press material kampas rem yang didalam cetakan dipanaskan sekaligus ditekan.

Yang mengalami penekanan paling besar adalah permukaan yang ditengah sehingga material kampas rem yang berada pada posisi tengah lebih padat dari pada yang pinggir. Dari tabel 4.1 hasil kekerasan yang didapat kampas rem merek Honda Genuine Parts lebih baik kualitasnya dibandingkan dengan merek Aspira dan Komachi, karena dari nilai kekerasannya merek Honda Genuine Parts lebih tinggi dari pada kedua merek.

\section{Hasil Pengujian Kekerasan Kampas Rem Sesudah Pengujian Keausan.}

Kampas rem yang sudah dilakukan pengereman sebanyak 60 kali dengan kecepatan $60 \mathrm{~km} / \mathrm{jam}$ pada pembebanan $6 \mathrm{~kg}$ dilakukan pengujiaan kekerasaan Rockwell, dimana hasil dari kekerasan rata-rata dapat dilihat pada tabel 3 .

Tabel 3. Hasil pengujian kekerasan kampas rem setelah pengujian keausan.

\begin{tabular}{|c|c|c|c|c|}
\hline No & $\begin{array}{c}\text { Merek } \\
\text { kampas rem }\end{array}$ & $\begin{array}{c}\text { Beban } \\
(\mathbf{k g})\end{array}$ & $\underset{(\mathrm{mm})}{\mathrm{D}}$ & $\begin{array}{l}\text { Kekerasan } \\
\text { (HRF) }\end{array}$ \\
\hline \multirow{6}{*}{1} & & 6 & $1 / 16$ & 94 \\
\hline & & 6 & $1 / 16$ & 105 \\
\hline & HONDA & 6 & $1 / 16$ & 102. \\
\hline & GENUIN & 6 & $1 / 16$ & 104 \\
\hline & PARTS & 6 & $1 / 16$ & 97 \\
\hline & \multicolumn{3}{|c|}{ Kekerasan rata-rata } & 100,4 \\
\hline \multirow{9}{*}{2} & \multirow{5}{*}{ ASPIRA } & 6 & $1 / 16$ & 62 \\
\hline & & 6 & $1 / 16$ & 64 \\
\hline & & 6 & $1 / 16$ & 73 \\
\hline & & 6 & $1 / 16$ & 76 \\
\hline & & 6 & $1 / 16$ & 60 \\
\hline & \multicolumn{3}{|c|}{ Kekerasan rata-rata } & 67 \\
\hline & & 6 & $1 / 16$ & 51 \\
\hline & & 6 & $1 / 16$ & 65 \\
\hline & & 6 & $1 / 16$ & 63 \\
\hline \multirow[t]{3}{*}{3} & KOMACHI & 6 & $1 / 16$ & 52 \\
\hline & & 6 & $1 / 16$ & 49 \\
\hline & \multicolumn{3}{|c|}{ Kekerasan rata-rata } & 56 \\
\hline
\end{tabular}

Dari tabel 3. diatas ketiga variasi merek hasil pengujian kekerasan kampas rem setelah pengujian keausan ternyata kekerasannya mengalami peningkatan dibandingkan dengan sebelum Pengujian keausan. Pada merek kampas rem Honda Genuine Parts kekerasan dari 95,9 HRF meningkat menjadi 100,4 HRF, merek Aspira dari $64 \mathrm{HRF}$ menjadi $67 \mathrm{HRF}$, merek Komachi dari 52,2 HRF menjadi 56 HRF. Meningkatnya kekerasan kampas rem disebabkan karena benda uji mengalami perubahan tempratur akibat dari gesekan disertai penekanan antara kampas rem dengan tromol yang 
menimbulkan panas diikuti pendinginan oleh udara. Akibat dari itu panas tersebut yang akan merubah susunan partikel menjadi lebih padat.

Pada umumnya yang harga murah memiliki kualitas yang rendah sebaliknya harga yang mahal biasanya kualitas tinggi. Dari ketiga variasi merek tersebut memiliki harga yang berbeda. Hasil penelitian tingkat kekerasan masing-masing merek kampas rem berbeda-beda yaitu merek Honda Genuine Parts kekerasannya : 95,8 HRF, merek Aspira : 64 HRF dan Komachi : 52,2 HRF, sedangkan kalau melihat dari tingkat keausan masing- masing merek kampas rem untuk merek Honda Genuine Parts yaitu : 0.002666 $\mathrm{mm}$, merek Aspira : $0.006207 \mathrm{~mm}$ dan Komachi : $0.007209 \mathrm{~mm}$. Hal ini merupakan bahwa semakin rendah kekerasan kampas rem tingkat keausan semakin besar dan semakin tinggi kekerasan kampas rem maka tingkat keausan semakin kecil. Hal Ini disebabkan karena material dasar kampas rem.

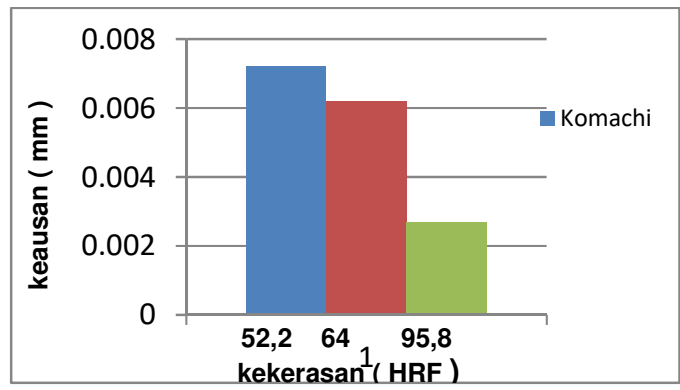

Gambar 5. Grafik hubungan antara kekerasan dengan tingkat keausan

Kampas rem merek Aspira dan Komachi tergolong kampas rem asbestos sedangkan merek Honda Genuine Parts termasuk non asbestos. Bahan dasar dari bahan non asbestos biasanya terdiri dari $4 \mathrm{~s} / \mathrm{d}$ 5 macam fiber di antaranya Kevlar,steel fiber,rock wool,cellulose dan carbon fiber yang memiliki serat panjang sedangkan kanvas rem dari bahan asbestos hanya memiliki I jenis fiber yaitu asbes yang merupakan komponen yang menimbulkan karsinogenik. Dari perbedaan ini makanya kanvas rem merek Honda Genuine Parts lebih unggul/ pakem, tahan aus dari pada merek Aspira maupun Komachi.

\section{Pengamatan Waktu Pengereman \\ Pengambilan waktu pengereman dilakukan pada saat beban pengereman $6 \mathrm{~kg}$,}

handle gas dilepas secara bersamaan seketika itu juga stopwatch dihidupkan sampai sepeda motor berhenti. pengambilan data pengereman terhitung disaat beban pengereman dilepas sampai sepeda motor berhenti.

Pada gambar 6 diatas menunjukkan bahwa Semakin tinggi kecepatan kendaraan dengan beban pengereman yang sama maka waktu pengereman akan semakin lama karena gaya mekanik yang dibutuhkan kampas rem untuk menghentikan tromol juga semakin besar.

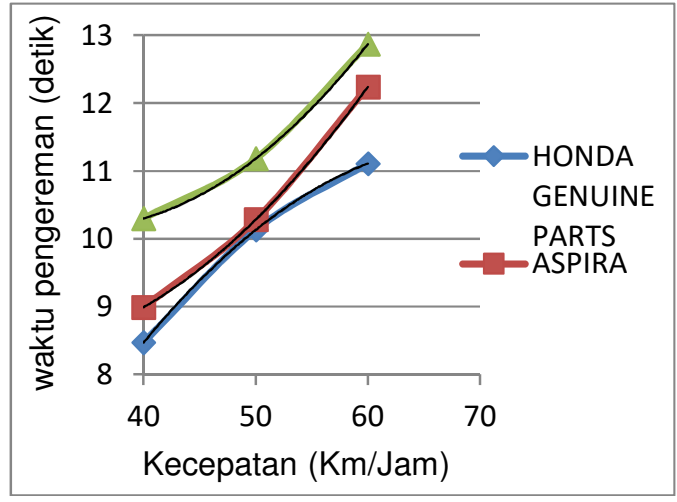

Gambar 6. Grafik hubungan antara kecepatan dan waktu pengereman

Dari hasil pengujian, ketiga variasi merek kampas rem menghasilkan waktu pengeremann yang berbeda-beda. Waktu pengereman pada merek Honda Genuine Parts yaitu 8,47 detik, merek Aspira yaitu 8,99 detik, merek Komachi yaitu 10,30 detik. Merek Honda genuine parts ternyata waktu pengeremannya lebih sedikit dibandingkan merek Aspira dan Komachi karena kampas rem merek Honda genuine parts terbuat dari material yang berkualitas yang mengakibatkan kampas rem merek Honda genuine lebih pakem, tahan aus, tahan panas dari pada merek Aspira dan Komachi.

\section{Pengamatan Jarak Pengereman}




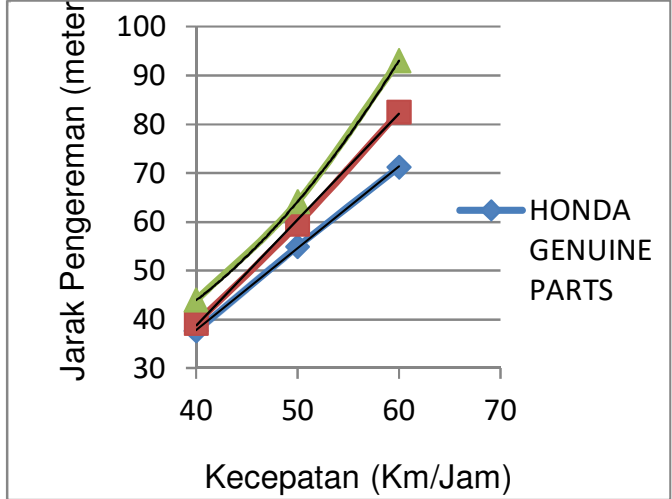

Gambar 7. Grafik hubungan antara kecepatan dan jarak pengereman

Gambar 7 menunjukkan hubungan antara kecepatan dan jarak pengereman. Semakin tinggi kecepatan pada beban pengereman yang sama, maka jarak pengereman semakin panjang karena gaya yang dibutuhkan kampas rem untuk menyerap energy juga semakain meningkat disisi lain energi yang diserap oleh rem harus sama dengan kerja yang dilakukan oleh gaya gesek. Dengan kecepatan $60 \mathrm{~km} / \mathrm{jam}$, serta beban pengereman yang sama $6 \mathrm{~kg}$. Ketiga merek kampas rem tersebut jarak pengeremannya berbeda beda. Merek Honda Genuine Parts yaitu jarak pengereman ratarata 71 meter, merek Aspira adalah 82 meter dan merek Komachi adalah 93 meter dikarenakan tingkat kepakeman kampas rem tersebut berbeda beda,

Kampas rem merek Honda Genuine Parts memiliki jarak pengereman terpendek dari pada merek aspira dan komachi, karena dari material pembuatan kampas rem berbeda-beda. Kampas rem merek Honda genuine dibuat dari $4 \mathrm{~s} / \mathrm{d} 5$ macam fiber di antaranya Kevlar, steel fiber, rock wool, cellulose dan carbon fiber yang memiliki serat panjang sedangkan kanvas rem merek Aspira dan komachi hanya memiliki I jenis fiber yaitu asbestos. Dari perbedaan inilah kampas rem merek Honda genuine parts lebih unggul, tahan aus, tingkat kekerasannya tinggi, selalu stabil dalam kondisi apapun dan tingkat kepakemannya tinggi dari pada merek Aspira maupun Komachi yang berdampak pada jarak pengereman.

\section{Pengamatan Tingkat Keausan}

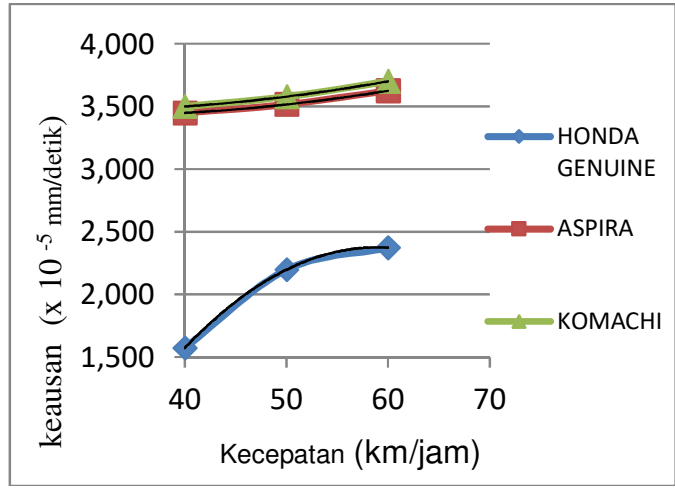

Gambar 8. Grafik hubungan antara kecepatan dan keausan

Gambar 8. Grafik hubungan antara kecepatan dan keausan. Semakin tinggi kecepatan dengan beban pengereman yang sama tingkat keausan juga semakin meningkat, pada kecepatan tinggi waktu yang dibutuhkan kampas rem untuk menghentikan putaran tromol juga semakin meningkat yang berdampak pada jarak pengereman yang panjang. Hal ini dikarenakan terjadi lebih lama/banyak kontak atau gesekan antar kampas rem dengan tromolnya yang berpengaruh terhadap besar kecilnya keausan, Dari ketiga merek kampas rem dengan kecepatan konstan $60 \mathrm{~km} / \mathrm{jam}$ serta beban pengereman $6 \mathrm{~kg}$, tingkat keausannya berbeda-beda yaitu merek Honda Genuin Parts keausannya 2,373 $\times 10^{-5} \mathrm{~mm} /$ detik, merek Aspira keausannya 3,626 x10-5 $\mathrm{mm} /$ detik dan merek Komachi keausannya $3,701 \times 10^{-5} \mathrm{~mm} /$ detik.

Didapat tingkat keausan merek Honda Genuine Parts lebih kecil dari pada merek Aspira dan Komachi karena kampas rem merek Honda Genuine Parts terbuat dari bahan/material yang berkualitas, tingkat kepakemannya serta nilai kekerasanya tinggi tahan panas, tahan aus, dan selalu setabil dalam kondisi apapun. Tingkat keausan terkecil terdapat pada kecepatan $40 \mathrm{~km} / \mathrm{jam}$ dengan merek Honda Genuin Parts dan tingkat keausan terbesar terdapat pada kecepatan $60 \mathrm{~km} / \mathrm{jam}$ dengan merek Komachi. Perbandingan persentase tingkat keausan terkecil pada merek Honda genuine parts dengan merek aspira yaitu $120 \%$ sedangkan persentase terbesar adalah $53 \%$. Kemudian merek Honda Genuine Parts dengan merek komachi persentase tingkat keausan terkecil adalah $155 \%$ sedangkan persentase terbesar adalah $56 \%$. 


\section{Kesimpulan}

Dari hasil penelitian dapat diambil kesimpulan bahwa sebagai berikut:

1. Terjadi keausan terkecil kampas rem terdapat pada kecepatan $40 \mathrm{~km} / \mathrm{jam}$ dan beban pengereman $6 \mathrm{~kg}$. Untuk merek Honda Genuine Parts keausannya adalah sebesar $1,574 \times 10^{-5} \mathrm{~mm} /$ detik, sedangkan merek Aspira keausannya $8,47 \times 10^{-5}$ $\mathrm{mm} /$ detik dan merek Komachi keausannya $3,500 \times 10^{-5} \mathrm{~mm} /$ detik.

2. Keausan terbesar kampas rem terjadi pada kecepatan $60 \mathrm{~km} / \mathrm{jam}$ dan beban pengereman $6 \mathrm{~kg}$. Untuk merek Honda Genuine Parts adalah sebesar 2,373 x 10-5 $\mathrm{mm} /$ detik, sedangkan merek Aspira keausannya $3,626 \times 10^{-5} \mathrm{~mm} /$ detik dan merek Komachi keausannya 3,701 x $10^{-5}$ $\mathrm{mm} /$ detik.

\section{Saran}

Untuk menyempurnakan hasil penelitian ini, maka beberapa hal berikut perlu dipertimbangkan.

1. Pada penelitian ini perlu diketahui terdapat kesulitan dalam melakukan pengukuran pengurangan tebal kampas rem di profil proyektor dibutuhkan ketelitian yang tinggi untuk menepatkan titik acuan untuk menentukan ukuran selanjutnya.

2. Perlu di butuhkan alat ukur yang memadai yang sesuai dengan penelitian untuk menghasilkan hasil yang lebik akurat dalam jangka waktu yang cepat.

\section{Daftar Pustaka}

Budiono, Eko (2010). tentang keausan kampas rem asli dan imitasi sepeda motor honda tiger, yamaha scorpio, suzuki thunder, dan kawasaki ninja. universitas gunadarma,

Dewanto, J., Wibowo.S., (2008). Kajian Pengeruh Gerak Relatif Sepatu Gesek Terhadap Efektifitas Pengereman Pada Jenis Rem Tromol Studi Kasus Untuk Rem Sepeda Motor. Seminar Nasional Teknik Mesin 3. Diakses 16 Januari 2009 dari www.petra.ac.id.

Hardianto,lan Siahaan., Yung,Hoo Sen,(2008). Kinerja Rem Tromol Terhadap Kinerja Rem Cakram Kendaraan Roda Dua Pada Pengujian Stasioner, Jurusan Teknik
Mesin Universitas Kristen Petra, Surabaya.

Hardianto,Ian Siahaan., Yung,Hoo Sen, (2008). Kinerja Rem Tromol Terhadap Kinerja Rem Cakram Kendaraan Roda Dua Pada Pengujian Stasioner, Jurusan Teknik Mesin Universitas Kristen Petra, Surabaya.

Haroen, Kartiwa Wawan dan Waskito, Arief Tri (2008). Peningkatan Standar Kanvas Rem Kendaraan Berbahan Baku Asbestos dan Non Asbestos (Celulose) Untuk Keamanan.Semarang JATENG.

Jama, Jalius (2008). Teknik Sepeda Motor Jilid 3 untuk SMK Departemen Pendidikan Nasional, Jakarta.

Lubi, (2001). Perancangan Kampas Rem Beralur dalam Usaha Meningkatkan Kinerja serta Umur dari Kampas Rem, Jurusan Teknik Mesin FTI-ITS Surabaya.

Maulana, Tri, (2010). Pembuatan Dan Pengujian Sifat Fisis Dan Mekanis Kampas Rem Dengan Bahan Dasar Arang Tempurung Kelapa Dengan Matriks Epoxy, Jurusan Teknik Mesin Univesitas muhamadiyah Surakarta.surakarta

Setianto,Imam, (2009). Pengaruh Variasi Temperatur Sintering Terhadap Ketahanan Aus Bahan Rem Sepatu Gesek,universitas muhamadiyah Surakarta, Surakarta.

Welianto,Andre (2010). Pengaruh Keausan Brake Pad Terhadap Waktu Pengereman Pada Pengujian Stationer, Jurusan Teknik Mesin Univesitas Kristen Petra,surabaya.

Yuliana, Desi (2007). Pengaruh Variasi Komposisi Serat Serabut Kelapa, Plastik Pet, Serbuk Alumunium Pada Sifat Fisik Dan Koefesien Gesek Bahan Kampas Rem Gesek. Jurusan teknik mesin fakultas teknik universitas muhammadiyah surakarta. Surakarta.

Yuwono,A.H., (2009). Buku Panduan Praktikum Karakterisasi Material 1 Pengujian Merusak (Destructive Testing), Departemen Metalurgi Dan Material Fakultas Teknik Universitas Indonesia, Jakarta. 